\title{
FREQUENCY OF HYPOCALCEMIA AND INDIRECT HYPERBILIRUBINEMIA IN PRETERM BABIES REMAIN ADMITTED IN INDEPENDENT UNIVERSITY HOSPITAL.
}

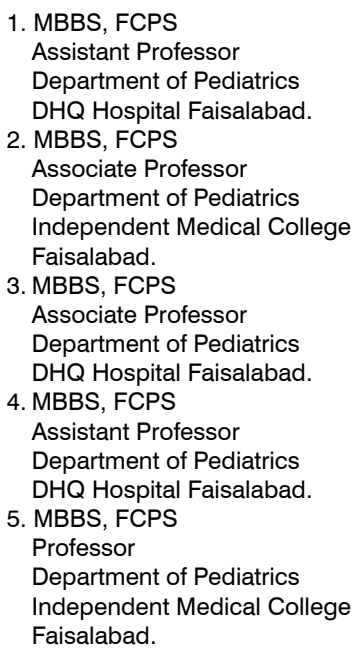

Correspondence Address:

Dr. Fazal Ellahi Bajwa

Department of Pediatrics

DHQ Hospital Faisalabad.

febajwa@gmail.com

Article received on: 04/09/2018

Accepted for publication:

01/07/2019

Received after proof reading:

28/08/2019

\begin{abstract}
Fazal Ellahi Bajwa ${ }^{1}$, Imran Sarwar ${ }^{2}$, Mahboob Alam ${ }^{3}$, Malik Rashid Nawaz ${ }^{4}$, Sadida Bahawal ${ }^{5}$
\end{abstract}
\begin{abstract}
Premature birth and low-birth weight are major causes of neonatal mortality, occurrence is $29 \%$. Complications of prematurity and its risk factors are comparatively lesser in late preterm babies. Preterm babies are at higher risk of development of Bronchopulmonary dysplasia, intraventricular hemorrhage, necrotizing enterocolitis, retinopathy of prematurity, patent ductus arteriosus sepsis, hypothermia, hypoglycemia, hypocalcaemia, and hyperbilirubinemia. No recent and current reliable data is available regarding frequency of hyperbilirubinemia and metabolic abnormalities in very preterm babies. Early detection of hyper-bilirubinemia, hypoglycemia and hypocalcaemia can help in better management and decrease neonatal morbidity and mortality. Objectives: To determine the frequency of hyperbilirubinemia and metabolic abnormalities in very preterm babies. Study Design: Cross sectional study. Setting: Neonatology department, Independent University Hospital, Faisalabad. Period: $14^{\text {th }}$ June 2016 to $13^{\text {th }}$ July 2017 . Material \& Methods: 120 very preterm singleton babies born between 28-34 weeks gestation, without lethal congenital anomalies and birth weight $>500$ gram presenting in neonatal emergency within first 24 hours of birth were included. Neonates born to mothers with diabetes mellitus, addiction, renal failure, hemoglubinopathies, Rh negative blood group along with neonates with toxemia, congenital pneumonia, congenital malformation, or any genetic syndrome were excluded. Results: Mean gestational age was $31 \pm 1.4$ weeks. Male patients were dominant $(52 \%)$ than the females $(48 \%)$. Hyperbilirubinemia, hypoglycemia and hypocalcemia was present in 68(57\%), 27(22.5\%) and 23(19\%) patients respectively. Conclusion: Hyperbilirubinemia and metabolic abnormalities are common in very preterm babies and by knowing the magnitude of these problems early preventive measure can be acquired to reduce the neonatal mortality and morbidity
\end{abstract}

Key word: Hyperbilirubinemia, Hypoglycemia and Hypocalcemia, Preterm.

Article Citation: Bajwa FE, Sarwar I, Alam Mahboob, Nawaz MR, Bahawal S. Frequency of hypocalcemia and indirect hyperbilirubinemia in preterm babies remain admitted in Independent University Hospital. Professional Med J 2019; 26(9):1557-1561. DOI: 10.29309/TPMJ/2019.26.09.4024

\section{INTRODUCTION}

Low birth weight and prematurity is a major factor contributing in neonatal mortality $28 \%$ cases. Incidence of prematurity among newborns is about $23 \% .^{1}$ In china preterm birth rate is 13.6 million most of them die during curly neonatal period due to fatal complication $72 \%$ of neonatal mortality is due to prematurity. ${ }^{2}$

World health organization define prematurity as any delivery before 37 wks of gestations, New born between $32-37$ wks are late preterm and 28 to 32 wks are very preterm and before 28 wks as extreme preterm babies. ${ }^{3,4}$
Risk of complications increase with decreasing gestational age very and extreme preterm are more prone to complications like respiratory distress syndrome and necrotizing enterocalitis. Hyperbilirubinemia ${ }^{5}$ and metabolic abnormalities are putting lot of burden on nurseries and cost to parents, society and health sectors. ${ }^{6,7}$

This study is designed for early detection of hyperbilirubinemia and metabolic abnormalities for better and improved management and outcome in preterm babies.

Direct complications of preterm birth were responsible for an estimated $35 \%$ of the world's 
3 million neonatal deaths in $2010^{8}$, making preterm birth the second most common cause of death in children under-five after pneumonia. Preterm birth also increases the risk of death due to other causes, especially neonatal infections. Hypothermia and malnutrition secondary to poor feeding further increase vulnerability ${ }^{9,10}$

$23 \%$ mortality in preterm neonates is due to hypothermia, hypoglycemia, hypocalcaemia and intra ventricular hemorrhage. ${ }^{11}$ Frequency of hypocalcaemia and hypoglycemia, and hyperbilirubinemia is $46 \%, 32 \%$ and $15 \% .^{12}$ Preterm birth is associated with many specific acute complications of immaturity including respiratory distress syndrome, intracranial hemorrhage, necrotising enterocolitis, and retinopathy of prematurity (ROP). In almost all high- and middle-income countries, preterm birth is the leading cause of child deaths.

\section{OBJECTIVE}

The objective of my study was to determine the frequency of hyper-bilirubinemia and metabolic abnormalities in very preterm babies.

\section{OPERATIONAL DEFINITIONS}

\section{Very Pretem Babies}

A neonate was considered as very preterm neonate if delivered between 28-32 weeks gestation, assessed from maternal last menstrual period (LMP).

\section{Hyperbilirubinemia}

It was defined as serum indirect bilirubin level $\geq 10 \mathrm{mg} / \mathrm{dl}$.

\section{Metabolic Abnormalities}

Metabolic abnormalities include hypoglycemia and hypocalcaemia.

Hypocalcaemia: total serum calcium level $<7$ $\mathrm{mg} / \mathrm{dl}$

Hypoglycemia: random blood glucose level $<45$ $\mathrm{mg} / \mathrm{dl}$

\section{MATERIALS AND METHODS} Study Design

A prospective cross sectional study.
Settings

Neonatology Department, Allied Hospital, Faisalabad.

\section{Duration of Study}

$14^{\text {th }}$ Jan 2017 to $13^{\text {th }}$ July 2017.

\section{Sample Size}

With confidence level of $95 \%$, absolute precision $8 \%$ and $p=17 \% \%^{5}$, sample size calculated using WHO sample size calculation formula came to be 120.

\section{Sampling Technique}

Non-probability consecutive sampling.

\section{SAMPLE SELECTION}

\section{Inclusion Criteria}

Very preterm singleton babies born between 28-32 weeks gestation, without lethal congenital anomalies and birth weight $>500$ gram presenting in neonatal emergency within first 24 hours of birth were included in the study.

\section{Exclusion Criteria}

1. Neonates born to mothers with diabetes mellitus, addiction, renal failure, and hemoglubinopathies.

2. Neonate with congenital toxemia, congenital pneumonia, congenital malformation, or any genetic syndrome.

3. Neonate born to a mother with $\mathrm{Rh}$ negative blood group.

\section{DATA COLLECTION PROCEDURE}

After the approval to carry out this study from the Ethical Review Committee, subjects meeting the operational definitions and the inclusion criteria were enrolled in the study after informed consent from the parents. Relevant data from the mother's file and other relevant data according to questionnaire were collected after complete examination of the child. Gestational age (calculated using the last day of menstrual period), weight and gender were noted. Serum $3 \mathrm{ml}$ sample was taken through vein puncture at the time of admission and sent to the same lab to check indirect bilirubin level, serum calcium and 
random blood glucose level. Results of all the investigations verified by pathologist were noted on the performa.

\section{Data Analysis}

The data was analyzed using SPSS version 17.1. Frequency was calculated along with percentage for qualitative variables including gender and presence of hyperbilirubinemia, hypo-glycaemia and hypocalcaemia. For quantitative variables like gestational age, weight, temperature and respiratory rate, mean $\pm S D$ was calculated. Effect modifiers like gestation age, weight and gender of the patient were stratified to find out the effect of these on the outcome, through chi square ( $p<0.05$ will, be considered significant).

\section{RESULTS}

120 premature born through 28 to 34 weeks of gestation were included in this study with birth weight more than 500 grams. Mean gestational age out these 120 babies was $31 \pm 1.4$ weeks. Range of weight recorded from minimum 0.91 to maximum $2.3 \mathrm{~kg}$. $95 \mathrm{~F}^{\circ}$ body temperature was recorded as minimum and $100 \mathrm{~F}^{\circ}$ as maximum with $97.8 \pm 0.85 \mathrm{~F}^{\circ}$ mean. Among these babies 30 breaths per minute minimum respiratory rate was recorded while 70 breath per minute was maximum. Mean Oxygen saturation through pulse oxymeter was $82.45 \%$ with minimum $70 \%$ to $91 \%$ There were $62(52 \%)$ males and $58(48 \%)$ Females.

Out of 120 patients, 55 (46\%) patients had gestational age $\leq 30$ weeks and $65(54.1 \%)$ had gestational age $>30$ weeks.

Mode of delivery was NVD in 52(43.3\%) and Csection in remaining $118(98.3 \%)$. Birth weight was less than $1 \mathrm{~kg}$ in $9(7.5 \%)$. Blood group was A positive in $42(35 \%) B$ positive in $41(34.2 \%) A B$ positive in 10 (8.3\%) and O positive in 26(22\%)

Out of these 120 babies 32 (27\%) were SGA $+88(73.3 \%)$ were normal for gestation $98 \mathrm{C}$ Mean serum bilirubin was $9.6 \mathrm{mg} / \mathrm{dl} \pm 2.31$ with minimum $6 \mathrm{mg} / \mathrm{dl}$ to maximum $15 \mathrm{mg} / \mathrm{dl}$.

Out of these 120, minimum blood sugar was
$35 \mathrm{mg} / \mathrm{dl}$ and maximum random blood sugar was $86 \mathrm{mg} / \mathrm{dl}$. There was mean serum calcium \pm 1.23 with minimum $6.8 \mathrm{mg} / \mathrm{dl}+$ maximum $1.8 \mathrm{mg} / \mathrm{dl} 68(57 \%)$ babies had hyperbilirubinemia while $52(43.3 \%)$ had normal bilirubin. Out of 120 patients, $27(22.5 \%)$ had hypoglycemia and $88(73.3 \%)$ had normal sugar level and 5 were normoghycemic. Out of 120 patients, 23 (19.1\%) patient had hypocalcaemia and 90 (75\%) had normal calcium level. 18(15\%) babies were hypocalcaemia and 102 (85\%) were normal.

\section{DISCUSSION}

According to world wide data from united states and developed countries preterm deliveries are an important cause of death in neonates. Although recent advances improve the outcome in premature infants. National neonatal research foundation indicates improvement in neonatal mortality and morbidity delivered at 28 - 34 week between $2007-20014 .^{13}$

Birth weight cutoffs are frequently focused in preterm neonates, changes in birth weight outcomes are due to addition of more mature neonatal having iutra uterine growth restrictions. ${ }^{14}$

High risk factors and poor outcomes are associated with very preterm, extreme prematurity. Infants born at 32 - 37 weeks covering almost $78 \%$ of preterm babies having better outcome as compared to preterm (22-30 wks) early and late complications are more in late preterm then term babies. ${ }^{15,16}$

Michael et al conducted study for incidence of hypocalcaemia in preterm following British guideline for hypocalcaemia and hypoglycemia shows $38 \%$ preterm infant having hypocalcaemia.

Nilium et al having study on hypocalcaemia and treatment modalities $12.5 \%$ dextrose with $10 \%$ dextrose - reported ${ }^{17}$ that $36 \%$ preterm having hypoglycemia. Other study conducted by Zilmaz et al level of vitamin $D$ in newborn and associated hypocalcaemia ${ }^{18} ; 36 \%$ preterm's were having hypocalcaemia and low level of Vit D. Van der Schoor L.W et al shows increased free unconjugated levels in preterms(26-31weeks). ${ }^{19}$ 
Valencil schuor et $\mathrm{al}^{20}$ conducted a study showing that more than $15 \%$ of preterm having hyperlirubinemia $28 \%$ preterm born through c-section and $16 \%$ born through vaginal delivery having jaundice.

My study showed that hyperbilirubinemia, hypoglycemia and hypocalcaemia was 65,27 and 23 babies common in small of gestational age preterm.

\section{CONCLUSION}

Hyperbilirubinemia and metabolic abnormalities like hypoglycemia and hypocalcemia are common problems in very preterm babies. The results of my study give the local burden of these complications that can be helpful in highlighting the importance of screening of such conditions so that special attention could be given to these babies for reduction of neonatal mortality and morbidity.

Copyright $\odot 01$ July, 2019.

\section{REFERENCES}

1. Kong X1, Xu F, Wu R, Wu H, Ju R, Zhao X, et al. Neonatal mortality and morbidity among infants between 24 to 31 complete weeks: A multicenter survey in China from 2013 to 2014. BMC Pediatr. 2016; 16:174.

2. Tsai M, Lien R, Chiang M, Hsu J, Fu R, Chu S, et al. Prevalence and morbidity of late preterm infants: Current status in a medical center of Northern Taiwan. Pediatrics \& Neonatology. 2012; 53: 171-77.

3. Gladstone M, Oliver C, Van den Broek N. Survival, morbidity, growth and developmental delay for babies born preterm in low and middle income countries - a systematic review of outcomes measured. PLoS One. 2015; 10(3):e0120566.

4. Shaprio-Mendoza CK, Lackritz EM. Epidemiology of late and moderate preterm birth. Semin Fetal Neonatal Med. 2012; 17(3):120-5.

5. Colin AA, McEvoy C, Castile RG. Respiratory morbidity and lung function in preterm infants of 32 to 36 weeks' gestational age. Pediatrics. 2010; 126:115-28.

6. Joseph KS, Nette F, Scott H, Vincer MJ. Prenatal corticosteroid prophylaxis for women delivering at late preterm gestation. Pediatrics. 2009; 124:e835-43.
7. Bulbul A, Cayonu N, Sanli ME, Uslu S. Evaluation of risk factors for development of severe hyperbilirubinemia in term and near term infants in Turkey. Pak $\mathrm{J}$ Med Sci. 2014; 30(5):1113-8.

8. Rawat M, Chandrasekharan P, Turkovich S, Barclay N, Perry K, Schroeder E, et al. Oral dextrose gel reduces the need for intravenous dextrose therapy in neonatal hypoglycemia. Biomed Hub. 2016; 1(3):448511.

9. Harding JE, Hegarty JE, Crowther CA, Edlin R, Gamble G, Alsweiler JM. Randomized trial of neonatal hypoglycaemia prevention with oral dextrose gel (hPOD): Study protocol. BMC Pediatr. 2015; 15:120.

10. Wackernagel $D$, Dube $M$, Blennow $M$, Tindberg $Y$. Continuous subcutaneous glucose monitoring is accurate in term and near-term infants at risk of hypoglycaemia. Acta Paediatr 2016; 105:917-23.

11. Harris DL, Weston PJ, Williams CE, Pleasants $A B$, Battin MR, Spooner CG, et al. Cot-side electroencephalography monitoring is not clinically useful in the detection of mild neonatal hypoglycemia. J Pediatr 2011; 159:755-60.

12. Ozdemirci $S$, Kut $A$, Salgur F. Late preterm and term birth: Neonatal hyperbilirubinemia and birth model. Fetal Pediatr Pathol. 2016; 35(4):213-9.

13. Bjelanović V, Raguž MJ, Galić M, Čuljak A, Bjelanović I, Tomić V. Perinatal complications in two cohort groups of preterm newborns in intensive care unit for children's diseases of university clinical hospital Mostar. Psychiatr Danub. 2017; 29 Suppl 4(Suppl 4):812-5.

14. Bulut C, Gursoy T, Ovali F. Short-term outcomes and mortality of late preterm infants. Balkan Med J. 2016; 33(2):198-203.

15. Kim WJ, Han YS, Ko HS, Park IY, Shin JC, Wie JH. Antenatal corticosteroids and outcomes of preterm small-for-gestational-age neonates in a single medical center. Obstet Gynecol Sci. 2018; 61:7-13.

16. Kutamba E, Lubega S, Mugalu J, Ouma J, Mupere E. Dextrose boluses versus burette dextrose infusions in prevention of hypoglycemia among preterms admitted at Mulago Hospital: An open label randomized clinical trial. Afr Health Sci. 2014; 14: 502-9.

17. Kong X1, Xu F, Wu R, Wu H, Ju R, Zhao X, et al. Neonatal mortality and morbidity among infants between 24 to 31 complete weeks: A multicenter survey in China from 2013 to 2014. BMC Pediatr. 2016; 16:174. 
18. Schonhaut L, Pérez M, Muñoz S. Association between neonatal morbidity, gestational age and developmental delays in moderate to late preterm children. Rev ChilPediatr. 2015; 86:415-25.

19. van der Schoor LW, Dijk PH, Verkade HJ, Kamsma $A C$, Schreuder AB, Groen $H$, et al. Unconjugated free bilirubin in preterm infants. Early Hum Dev. 2017; 1067:25-32.
20. Lemons JA, Bauer CR, Oh W, Korones SB, Papile LA, Stoll BJ, et al. Very low birth weight outcomes of the national institute of child health and human development neonatal research network, January 1995 through december 1996. NICHD neonatal research network. Pediatrics. 2001; 107:E1.

\section{AUTHORSHIP AND CONTRIBUTION DECLARATION}

\begin{tabular}{|c|c|c|c|}
\hline Sr. \# & Author-s Full Name & Contribution to the paper & Author $=\mathbf{s}$ Signature \\
\hline 1 & Fazal Ellahi Bajwa & Data collection. & Gallabi \\
\hline 2 & Imran Sarwar & Review. & \\
\hline 3 & Mahboob Alam & Statistics. & \\
\hline 4 & Malik Rashid Nawaz & Statistics. & Raokid. \\
\hline 5 & Sadida Bahawal & Paper writer. & \\
\hline
\end{tabular}

